OPEN ACCESS

Edited by:

Ramon Rios,

University of Southampton,

United Kingdom

Reviewed by:

Weaam Ebrahim,

Mansoura University, Egypt

Yonghong Liu,

Chinese Academy of Sciences

(CAS), China

${ }^{*}$ Correspondence:

Lin Chen

Ichenchina@163.com

Gang Ding

gding@implad.ac.cn

Wancun Zhang

zhangwancun@126.com

Specialty section:

This article was submitted to

Organic Chemistry,

a section of the journal

Frontiers in Chemistry

Received: 23 October 2020 Accepted: 01 March 2021

Published: 21 April 2021

Citation:

Guo Q, Chen J, Ren Y, Yin Z, Zhang J, Yang $B$, Wang $X$, Yin $W$, Zhang $W$,

Ding $G$ and Chen L (2021)

Hydrazine-Containing Heterocycle

Cytochalasan Derivatives From

Hydrazinolysis of Extracts of a Desert

Soil-Derived Fungus Chaetomium

madrasense 375

Front. Chem. 9:620589.

doi: 10.3389/fchem.2021.620589

\section{Hydrazine-Containing Heterocycle Cytochalasan Derivatives From Hydrazinolysis of Extracts of a Desert Soil-Derived Fungus Chaetomium madrasense 375}

\author{
Qingfeng Guo ${ }^{1}$, Jinhua Chen ${ }^{2}$, Yuwei Ren ${ }^{1}$, Zhenhua Yin ${ }^{1}$, Juanjuan Zhang ${ }^{1}$, \\ Baocheng Yang ${ }^{1}$, Xuewei Wang ${ }^{3}$, Wenbing Yin ${ }^{3}$, Wancun Zhang ${ }^{4 *}$, Gang Ding ${ }^{5 *}$ and \\ Lin Chen ${ }^{1 *}$
}

\begin{abstract}
' Zhengzhou Key Laboratory of Synthetic Biology of Natural Products, Zhengzhou Key Laboratory of Medicinal Resources Research, Comprehensive Utilization of Edible and Medicinal Plant Resources Engineering Technology Research Center, Huanghe Science and Technology College, Zhengzhou, China, ${ }^{2}$ Department of Pharmacy, Affiliated Cancer Hospital of Zhengzhou University, Henan Cancer Hospital, Zhengzhou, China, ${ }^{3}$ State Key Laboratory of Mycology, Institute of Microbiology, Chinese Academy of Sciences, Beijing, China, ${ }^{4}$ Henan Key Laboratory of Children's Genetics and Metabolic Diseases, Children's Hospital Affiliated to Zhengzhou University, Zhengzhou, China, ${ }^{5}$ Institute of Medicinal Plant Development, Chinese Academy of Medical Science and Union Medical College, Beijing, China
\end{abstract}

"Diversity-enhanced extracts" is an effective method of producing chemical libraries for the purpose of drug discovery. Three rare new cytochalasan derivative chaetoglobosins $\mathrm{B}_{1}-\mathrm{B}_{3}$ (1-3) were obtained from chemically engineered crude broth extracts of Chaetomium madrasense 375 prepared by reacting with hydrazine monohydrate and four known metabolite chaetoglobosins (4-7) were also identified from the fungus. The structures were identified by NMR and MS analysis and electronic circular dichroism simulation. In addition, the antiproliferative activities of these compounds were also evaluated, and the drug-resistant activities of cytochalasans were evaluated for the first time. Compound $\mathbf{6}$ possessed potent activity against four human cancer cells (A549, HCC827, SW620, and MDA-MB-231), and two drug-resistant HCC827 cells (Gefitinib-resistant, Osimertinib-resistant) compared with the positive controls.

Keywords: diversity-enhanced, cytochalasans, antiproliferative activity, chaetomium madrasense, hydrazinolysis

\section{INTRODUCTION}

Natural products have played an important role in the development of novel drugs because of their established structural diversity (Newman and Cragg, 2016). However, research on natural products within the pharmaceutical industry has recently declined, and it has become more and more difficult to obtain compounds bearing skeletally novel structures from natural sources (Bradshaw et al., 2001; Wolfender and Queiroz, 2012). Chemical modification of natural product extracts provides a new strategy for discovering of diverse structurally active molecules. Recently, there have been several reports (Lopez et al., 2007; Mendez et al., 2011; Salazar et al., 2011; Ramallo et al., 2012; Kikuchi et al., 2014; Wu et al., 2015; Garcia et al., 2016) on the application of chemical alteration of natural product extracts to obtain new or bioactive compounds. 
Cytochalasans comprise a large group of polyketide synthase and non-ribosomal peptide synthetase-derived fungal metabolites with a wide range of biological activities (Scherlach et al., 2010). The macrocyclic structure of most cytochalasans contains carbonyl functional groups, which could react with hydrazine to form either hydrazones or acyl hydrazides that rarely emerge in nature. This transformation could increase the nitrogen content and nucleophilic character of further reactions (Feher and Schmidt, 2003). In previous studies, we reported several bioactive cytochalasans that were isolated from C. madrasense 375 derived from desert soil (Guo et al., 2019). To gain more novel cytochalasan-like bioactive compounds, a chemical transformation of crude broth extracts of C. madrasense 375 with hydrazine monohydrate was performed, followed by purification of reaction products, which offered three new cytochalasans derivatives chaetoglobosins $B_{1}-B_{3}$ (1-3), and known chaetoglobosin B (4) (Sekita et al., 1982, 1983) chaetoglobosin D (5) (Sekita et al., 1982, 1983), chaetoglobosin E (6) (Sekita et al., 1976), and cytoglobosin A (7) (Cui et al., 2010) were also isolated from the unreactive raw extract of this fungus. In this paper, we present the isolation, structure elucidation, bioactivities, and plausible synthesis pathways of these compounds.

\section{MATERIALS AND METHODS \\ General Experimental Procedures}

CD spectra were determined on a JASCO J-810 spectropolarimeter (JASCO Corporation), and UV data were recorded using a PERSEE UV-VIS spectrophotometer T9 (Beijing, China). NMR experiments were carried out on a Bruker AVANCE III 400 NMR spectrometer (Bruker, Germany), using tetramethylsilane (TMS) or solvent signals as an internal reference. HRESIMS data were collected on an Agilent 6250 TOF LC/MS, and ESIMS data were acquired on an Agilent 1200 series LC/MS system. Semipreparative HPLC was run on a Calmflow ${ }^{\text {plus }}$ system that was equipped with a YMC Pack ODS-A column $(10 \mathrm{~mm} \times 250 \mathrm{~mm} 5 \mu \mathrm{m}$, Japan $)$ and a $50 \mathrm{D}$ UV-vis Detector (Lumiere Tech Ltd) and with a flow rate of 2.0 $\mathrm{ml} / \mathrm{min}$. Packing materials for column chromatography were silica gel (200-300 mesh; Qingdao Marine Chemical Factory, Qingdao, China), ODS (YMC, Japan), and Sephadex LH-20 (GE Healthcare BioSciences AB, Sweden). All chemicals used in the study were of analytical grade.

\section{Fungal Material and Fermentation}

The samples of the fungus C. madrasense375 (CCTCC M 2019517 CLC375) were collected from a soil sample obtain at Hotan city, XinJiang province, People's Republic of China, and identified by one of the authors (XueWei Wang). The fungus was identified as $C$. madrasense according to its internal transcribed spacer (ITS) sequence of ITS rDNA (Supplementary Figure 34) and beta-tubulin encoding gene (Supplementary Figure 33) from genomic DNA, as well as its morphological features. A phylogenetic tree was constructed based on the sequence of the partial beta-tubulin gene from $C$. madrasense and other species in the genus Chaetomium, with Aspergillus nidulans as the outgroup (Supplementary Figure 32). The sequence of the strain was deposited in GenBank with accession number KP269060.1. The fungal strain was maintained on potato dextrose agar (PDA) at $25^{\circ} \mathrm{C}$ for 7 days to prepare the seed culture. Agar plugs were cut into small pieces (approximately $1 \mathrm{~cm} \times 1 \mathrm{~cm}$ ) and inoculated into four $500 \mathrm{ml}$ Erlenmeyer flasks containing $200 \mathrm{ml}$ of synthetic dropout Medium (SD, peptone $10.0 \mathrm{~g} / \mathrm{L}$, dextrose $40.0 \mathrm{~g} / \mathrm{L}$ ) and incubated at $26^{\circ} \mathrm{C}$ for 10 days on a rotary shaker $(120 \mathrm{rpm})$. The obtained liquid seeds were transferred into fifty $500 \mathrm{ml}$ Erlenmeyer flasks, each containing $200 \mathrm{ml}$ of the sterilized synthetic dropout medium and incubated at $26^{\circ} \mathrm{C}$ for 35 days on a rotary shaker $(120 \mathrm{rpm})$ before harvest. The culture was filtered to separate broth and mycelia, and then extracted by ethyl acetate (three times) at room temperature. The combined extracts of broth and mycelia were dried under reduced pressure to give a dark brown gum $(8.3 \mathrm{~g})$. The crude extract was then suspended in $\mathrm{H}_{2} \mathrm{O}$ and extracted with petroleum ether, EtoAc, and $n$-BuOH, respectively. The EtoAc extract $(5.6 \mathrm{~g})$ was packed with cytochalasans based on the analysis of TLC and LC-MS experiments and divided into two parts, one (4 g) prepared for chemical modification, another $(1.6 \mathrm{~g})$ for metabolite research directly.

\section{Chemical Modification of Extraction and Isolation}

An $\mathrm{EtOH}$ solution of the dry extract (3\% wt/vol) containing hydrazine monohydrate (6\% vol/vol) and three drops of hexahydropyridine was stirred under reflux at $75^{\circ} \mathrm{C}$ for $8 \mathrm{~h}$, and the solvent was removed under reduced pressure. The preliminary experiment was carried out on a $100 \mathrm{mg}$ scale to obtain modified production successfully and prove feasibility. The obtained residue was subjected to an ODS column eluted with $\mathrm{CH}_{3} \mathrm{OH} / \mathrm{H}_{2} \mathrm{O}(30,50,70$, and $100 \%, v / v)$ to afford four main fractions (A-D). Fraction $\mathrm{C}$ was chromatographed by Sephadex LH-20 (100\% MeOH) to give 10 subfractions (C-1-C$10)$, Fraction $\mathrm{C}-1$ was further purified via semipreparative HPLC (37\% $\mathrm{MeCN}$ in $\mathrm{H}_{2} \mathrm{O}$ ) to yield chaetoglobosin $\mathrm{B}_{1}\left(1 ; 2.5 \mathrm{mg}, t_{\mathrm{R}}\right.$ $16.1 \mathrm{~min})$. Fraction $\mathrm{C}-3$ was further purified by semipreparative HPLC using $32 \%$ acetonitrile in water to afford chaetoglobosin $\mathrm{B}_{3}\left(3 ; 5.8 \mathrm{mg}, t_{\mathrm{R}} 32.3 \mathrm{~min}\right)$. Chaetoglobosin $\mathrm{B}_{2}\left(2 ; 4.3 \mathrm{mg}, t_{\mathrm{R}}\right.$ $24.6 \mathrm{~min}$ ) was purified from subfraction C-5 by RP-HPLC using $35 \%$ acetonitrile in water. The unreactive raw extract $(1.6 \mathrm{~g})$ was subjected to Sephadex $\mathrm{LH}-20\left(\mathrm{CH}_{2} \mathrm{Cl}_{2} / \mathrm{MeOH}, v / v, 1: 1\right)$ to yield five fractions (Fr1-Fr5). Fraction 3 was separated using semipreparative $\mathrm{HPLC}\left(45 \% \mathrm{MeCN}\right.$ in $\mathrm{H}_{2} \mathrm{O}$ with $0.1 \% \mathrm{HCOOH}$ ) to give chaetoglobosin $\mathrm{B}\left(4 ; 8.7 \mathrm{mg}, t_{\mathrm{R}} 31.5 \mathrm{~min}\right)$, chaetoglobosin $\mathrm{D}\left(5 ; 6.3 \mathrm{mg}, t_{\mathrm{R}} 24.9 \mathrm{~min}\right)$, and chaetoglobosin $\mathrm{E}\left(6 ; 4.6 \mathrm{mg}, t_{\mathrm{R}}\right.$ $21.7 \mathrm{~min})$. Cytoglobosin A (7; $\left.1.3 \mathrm{mg}, t_{\mathrm{R}} 19.4 \mathrm{~min}\right)$ was obtained from fraction 4 using semipreparative $\mathrm{HPLC}\left(50 \% \mathrm{MeCN}\right.$ in $\mathrm{H}_{2} \mathrm{O}$ with $0.1 \% \mathrm{HCOOH}$ ).

Chaetoglobosin $\mathrm{B}_{1}$ (1): white amorphous powder; UV $(\mathrm{MeOH}) \lambda_{\max }(\log \varepsilon) 281 \mathrm{~nm}(2.00), 225 \mathrm{~nm}$ (3.02), and $221 \mathrm{~nm}$ (3.01); for ${ }^{1} \mathrm{H}$ NMR (400 MHz) and ${ }^{13} \mathrm{C}$ NMR (100 MHz) data, see Tables 1, 2; HR-ESI-MS $\mathrm{m} / z 543.2950[\mathrm{M}+\mathrm{H}]^{+}$(calcd for $\left.\mathrm{C}_{32} \mathrm{H}_{39} \mathrm{~N}_{4} \mathrm{O}_{4}, 543.2966\right)$. 
TABLE 1 | ${ }^{1} \mathrm{H}$ NMR spectroscopic data ( $\delta$ in ppm, $\mathrm{J}$ in $\mathrm{Hz}$ ) for compounds $\mathbf{1}-\mathbf{3}$

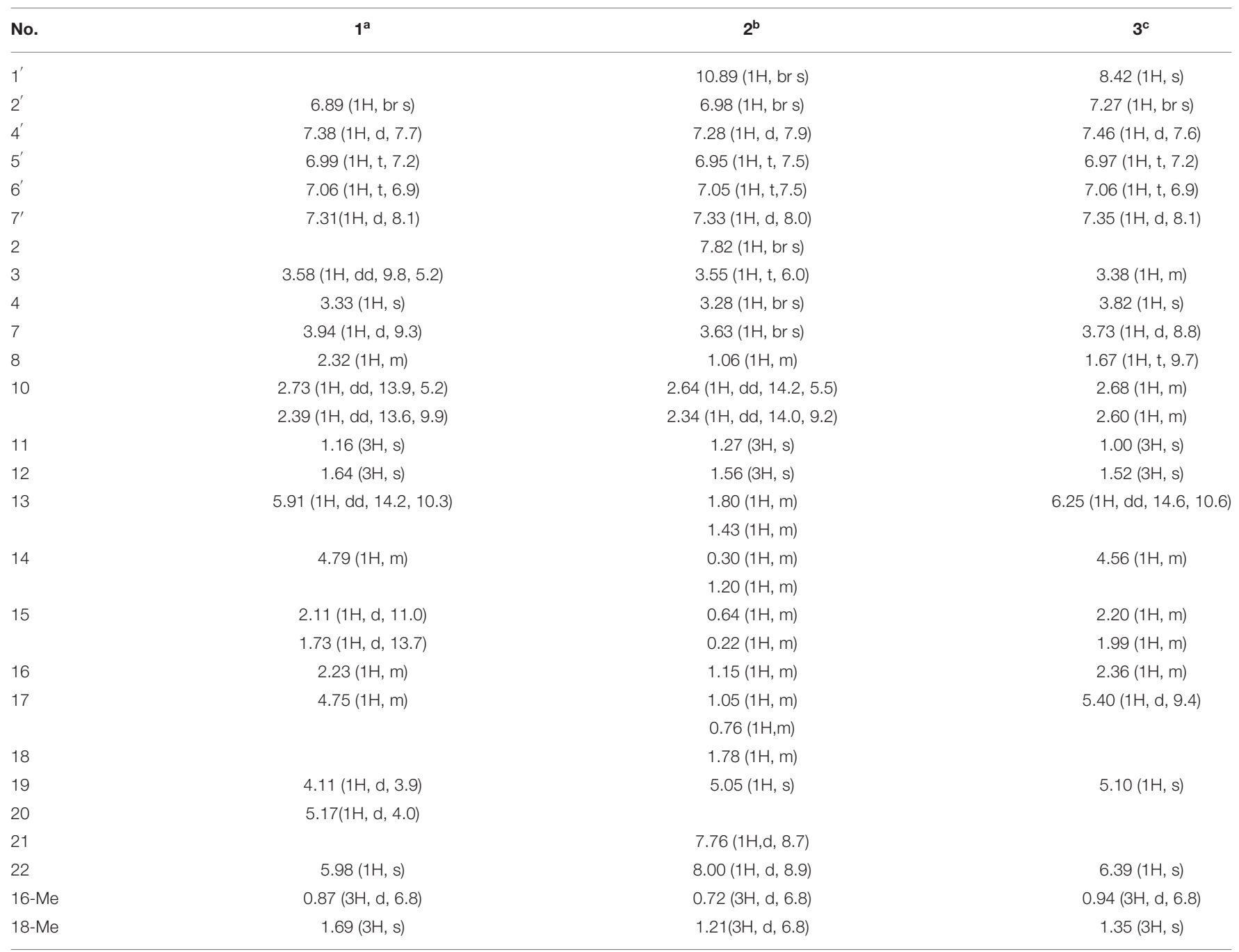

${ }^{a}$ Measured in $C D_{3} O D .{ }^{b}$ Measured in DMSO-d $6 .{ }^{c}$ Measured in DMSO-d 6 with one drop $C D_{3} O D$.

Chaetoglobosin $\mathrm{B}_{2}$ (2): white amorphous powder; UV $(\mathrm{MeOH}) \lambda_{\max }(\log \varepsilon) 279 \mathrm{~nm}(1.21)$ and $211 \mathrm{~nm}$ (3.23); for ${ }^{1} \mathrm{H}$ NMR (400 MHz), and ${ }^{13} \mathrm{C}$ NMR $(100 \mathrm{MHz})$ data, see Tables 1, 2; HR-ESI-MS $m / z$ 529.3184 $[\mathrm{M}+\mathrm{H}]^{+}$(calcd for $\mathrm{C}_{32} \mathrm{H}_{41} \mathrm{~N}_{4} \mathrm{O}_{3}, 529.3173$ ).

Chaetoglobosin $\mathrm{B}_{3}$ (3): white amorphous powder; UV $(\mathrm{MeOH}) \lambda_{\max }(\log \varepsilon) 282 \mathrm{~nm}(0.31)$, and $221 \mathrm{~nm}$ (1.57); $\operatorname{ECD}(\mathrm{MeOH}) \lambda_{\max }(\Delta \varepsilon)=286 \mathrm{~nm}(+14.5), 224$ (-27.2); for ${ }^{1} \mathrm{H}$ NMR (400 MHz) and ${ }^{13} \mathrm{C}$ NMR (100 MHz) data, see Tables 1, 2; HR-ESI-MS $\mathrm{m} / z$ 567.2738 $[\mathrm{M}+\mathrm{H}]^{+}$(calcd for $\mathrm{C}_{32} \mathrm{H}_{35} \mathrm{~N}_{6} \mathrm{O}_{4}, 567.2714$ ).

\section{Quantum-Chemical Calculation}

Monte Carlo conformational searches were run with the Spartan 14 software using the Merck Molecular Force Field (MMFF). The Selected conformers, which account for more than $1 \%$ of the Boltzmann distribution, were initially optimized at the B3LYP/6$31+\mathrm{G}(\mathrm{d}, \mathrm{p})$ level with the conductor-like polarizable continuum model (CPCM) conductor calculation in methanol solvent. The conformers of 3 were identified via ECD simulation using the time-dependent density functional theory (TD-DFT) method at the B3LYP/6-31+G (d, p) level with methanol as solvent, and the rotational strengths of 30 excited states were calculated. ECD spectra of compound 3 were obtained using the SpecDis 1.6 (University of Würzburg, Würzburg, Germany) and GraphPad Prism 5 (University of California San Diego, USA) software by applying Gaussian band shapes with sigma $=0.3 \mathrm{eV}$ from dipole-length rotational strengths (Guo et al., 2019).

\section{Antiproliferative Assay}

Antiproliferative activity was performed against four human cancer cell lines (A549, SW620, MDA-MB-231, and HCC827), together with two drug-resistant (gefitinib, osimertinib) HCC827cell lines, applying the 3-(4,5-dimethyl-2-thiazolyl)2,5-diphenyl-2-H-tetrazolium bromide (MTT) method (Chen et al., 2014) with the DDP (cisplatin, Sigma), gefitinib, and 
TABLE $2 \mid{ }^{13} \mathrm{C}$ NMR spectroscopic data ( $\delta$ in ppm) for compounds $\mathbf{1 - 3}$.

\begin{tabular}{|c|c|c|c|}
\hline NO & $1^{a}$ & $2^{b}$ & $3^{c}$ \\
\hline $1^{\prime} a$ & $138.1 \mathrm{C}$ & $136.2 \mathrm{C}$ & $136.2 \mathrm{C}$ \\
\hline $2^{\prime}$ & $124.6 \mathrm{CH}$ & $123.1 \mathrm{CH}$ & $123.8 \mathrm{CH}$ \\
\hline $3^{\prime}$ & $112.1 \mathrm{C}$ & $110.5 \mathrm{C}$ & $110.7 \mathrm{C}$ \\
\hline $3^{\prime} \mathrm{a}$ & $128.6 \mathrm{C}$ & $127.0 \mathrm{C}$ & $127.5 \mathrm{C}$ \\
\hline $4^{\prime}$ & $119.3 \mathrm{CH}$ & $118.0 \mathrm{CH}$ & $118.2 \mathrm{CH}$ \\
\hline $5^{\prime}$ & $119.8 \mathrm{CH}$ & $118.3 \mathrm{CH}$ & $118.3 \mathrm{CH}$ \\
\hline $6^{\prime}$ & $122.3 \mathrm{CH}$ & $121.0 \mathrm{CH}$ & $120.9 \mathrm{CH}$ \\
\hline $7^{\prime}$ & $112.3 \mathrm{CH}$ & $111.4 \mathrm{CH}$ & $111.5 \mathrm{CH}$ \\
\hline 1 & $179.2 \mathrm{C}$ & $173.8 \mathrm{C}$ & $175.8 \mathrm{C}$ \\
\hline 3 & $60.1 \mathrm{CH}$ & $56.4 \mathrm{CH}$ & $58.3 \mathrm{CH}$ \\
\hline 4 & $53.6 \mathrm{CH}$ & $50.9 \mathrm{CH}$ & $47.1 \mathrm{CH}$ \\
\hline 5 & $128.4 \mathrm{C}$ & $125.3 \mathrm{C}$ & $126.1 \mathrm{C}$ \\
\hline 6 & $134.3 \mathrm{C}$ & $134.4 \mathrm{C}$ & $132.6 \mathrm{C}$ \\
\hline 7 & $71.2 \mathrm{CH}$ & $69.8 \mathrm{CH}$ & $68.7 \mathrm{CH}$ \\
\hline 8 & $56.4 \mathrm{CH}$ & $50.3 \mathrm{CH}$ & $55.8 \mathrm{CH}$ \\
\hline 9 & $51.5 \mathrm{C}$ & $53.0 \mathrm{C}$ & $49.1 \mathrm{C}$ \\
\hline 10 & $32.5 \mathrm{CH}_{2}$ & $31.9 \mathrm{CH}_{2}$ & $31.9 \mathrm{CH}_{2}$ \\
\hline 11 & $17.4 \mathrm{CH}_{3}$ & $17.1 \mathrm{CH}_{3}$ & $16.9 \mathrm{CH}_{3}$ \\
\hline 12 & $14.7 \mathrm{CH}_{3}$ & $15.2 \mathrm{CH}_{3}$ & $14.4 \mathrm{CH}_{3}$ \\
\hline 13 & $129.9 \mathrm{CH}$ & $25.2 \mathrm{CH}_{2}$ & $130.7 \mathrm{CH}$ \\
\hline 14 & $135.1 \mathrm{CH}$ & $27.7 \mathrm{CH}_{2}$ & $133.1 \mathrm{CH}$ \\
\hline 15 & $43.0 \mathrm{CH}$ & $34.6 \mathrm{CH}_{2}$ & $42.3 \mathrm{CH}_{2}$ \\
\hline 16 & $33.1 \mathrm{CH}$ & $31.5 \mathrm{CH}$ & $32.4 \mathrm{CH}$ \\
\hline 17 & $137.8 \mathrm{CH}$ & $30.2 \mathrm{CH}_{2}$ & $136.5 \mathrm{CH}$ \\
\hline 18 & $133.5 \mathrm{C}$ & $34.4 \mathrm{CH}$ & $133.4 \mathrm{C}$ \\
\hline 19 & $82.4 \mathrm{CH}$ & $75.8 \mathrm{CH}$ & $75.6 \mathrm{CH}$ \\
\hline 20 & $73.0 \mathrm{CH}$ & $165.5 \mathrm{C}$ & $143.4 \mathrm{C}$ \\
\hline 21 & $147 \mathrm{C}$ & $123.5 \mathrm{CH}$ & $128.9 \mathrm{C}$ \\
\hline 22 & $102.6 \mathrm{CH}$ & $125.1 \mathrm{CH}$ & $105.2 \mathrm{CH}$ \\
\hline 23 & $155 C$ & $163.0 \mathrm{C}$ & $152.0 \mathrm{C}$ \\
\hline 16-Me & $21.8 \mathrm{CH}_{3}$ & $21.0 \mathrm{CH}_{3}$ & $21.6 \mathrm{CH}_{3}$ \\
\hline 18-Me & $12.7 \mathrm{CH}_{3}$ & $21.9 \mathrm{CH}_{3}$ & $9.6 \mathrm{CH}_{3}$ \\
\hline
\end{tabular}

${ }^{a}$ Measured in $C D_{3} O D$. ${ }^{b}$ Measured in DMSO-d $d_{6}{ }^{C}$ Measured in DMSO-d $d_{6}$ with one drop $C D_{3} O D$.

osimertinib as positive controls, respectively. The cell lines were cultured in RPMI-1640 medium supplemented with $10 \%$ FBS at $37^{\circ} \mathrm{C}$ under a humidified atmosphere of $5 \% \mathrm{CO}_{2}$. Cells $\left(3 \times 10^{4} /\right.$ well $)$ were seeded in a 96 -well plate and incubated for $24 \mathrm{~h}$. The test compounds at different concentrations were added to each well and further incubated for 24 or $48 \mathrm{~h}$ under the same conditions. Then, $10 \mu \mathrm{l}$ of the MTT was added to each well at a concentration of $5 \mathrm{mg} / \mathrm{ml}$ and incubated for $4 \mathrm{~h}$. The medium containing MTT was then gently replaced by DMSO and pipetted to dissolve any formazan crystals formed. Absorbance was then determined on a Tecan Sunrise microplate reader at $490 \mathrm{~nm}$. The concentration required to inhibit cell growth by $50 \%\left(\mathrm{IC}_{50}\right)$ was calculated from inhibition curves.

\section{RESULTS AND DISCUSSION}

The ethyl acetate extract of C. madrasense 375 was obtained from the submerged fermentation liquid and divided into two parts; part 1 was treated with hydrazine monohydrazine and hexahydropyridine (catalyst) to give a chemically modified production. HPLC (Supplementary Figure 35) and ${ }^{13} \mathrm{C}$ NMR (Supplementary Figure 36) were performed to analyze changes in the extract. Modified production and raw extract were further separated and purified through reversed-phase C18 (ODS) column chromatography, Sephadex LH-20, as well as semipreparative HPLC to afford compounds 1-7 (Figure 1).

\section{Identification of Compounds}

Chaetoglobosin $B_{1}$ (1) was obtained as a white amorphous powder. The molecular ion peak in the HR-ESI-MS $\left(\mathrm{m} / z \quad 543.2950 \quad[\mathrm{M}+\mathrm{H}]^{+}\right.$(Supplementary Figure 7), calcd for 543.2966, $\mathrm{C}_{32} \mathrm{H}_{39} \mathrm{~N}_{4} \mathrm{O}_{4}$ ) and NMR data indicated that the molecular formula of $\mathbf{1}$ is $\mathrm{C}_{32} \mathrm{H}_{38} \mathrm{~N}_{4} \mathrm{O}_{4}$ (16 unsaturations). Combined ${ }^{1} \mathrm{H}$ and ${ }^{13} \mathrm{C}$ NMR spectra (Tables 1, 2; Supplementary Figures 1, 2) and HSQC (Figure 2; Supplementary Figure 4), HMBC (Figure 2; Supplementary Figure 5) experiments indicated the presence of four methyl groups, two methylene units, seven methine units, one quaternary carbon, 16 olefinic or aromatic carbons, as well as one amide carbonyl carbon. The characteristic signals of ${ }^{1} \mathrm{H}$ and ${ }^{13}$ C NMR (Tables 1, 2; Supplementary Figures 1, 2) suggested that compound 1 was most likely a chaetoglobosin derivative (Gao et al., 2019; Chen et al., 2020). Detailed analysis of the 1D (Supplementary Figures 1, 2) spectra of $\mathbf{1}$ revealed a close similarity with those reported chaetogobosin B (4) (Sekita et al., $1982,1983)$, except that the C-20, C-21, C-22, and C-23 signals at $\delta_{\mathrm{C}} 197.3,136.0,136.4$, and 201.3 in chaetogobosin B (4) were replaced by $\delta_{\mathrm{C}} 73.0,147.0,102.6$, and 155.0 in $\mathbf{1}$, respectively. The chemical shift values of C-20 $\left(\delta_{\mathrm{C}}=73.0\right)$ and C- $23\left(\delta_{\mathrm{C}}=155.0\right)$ revealed the connection with the additional nitrogen or oxygen atom. Comparison of the molecular formula for chaetogobosin $\mathrm{B}(4)$ and $\mathbf{1}, \mathbf{1}$ also was found to contain two additional nitrogen atoms, with the C-20, C-21, C-22, and C-23 carbons to constitute a pyridazin ring. Furthermore, the HMBC correlations (Figure 2; Supplementary Figure 5) from H-20 to C-18, C-19 and C-21, $\mathrm{H}-22$ to $\mathrm{C}-21$ and $\mathrm{C}-23$, and from $\mathrm{H}-8$ to $\mathrm{C}-23$, as well as ${ }^{1} \mathrm{H}-{ }^{-1} \mathrm{H}$ COZY correlations (Figure 2; Supplementary Figure 3) of $\mathrm{H}-20 / \mathrm{H}-19$ supported this deduction. In the NOESY spectrum (Supplementary Figure 6), the relative configurations of $\mathrm{H}-4$ and $\mathrm{H}-8$ were assigned as $\beta$-orientations based on cross-peaks of $\mathrm{H}-4 / \mathrm{H}-8 / \mathrm{H}-14$, and $\mathrm{H}-7 / \mathrm{H}-13$ implied that $\mathrm{H}-7$ was $\alpha$ orientation. Furthermore, correlations from $\mathrm{H}-13$ and $\mathrm{H}-17$ to $15 \alpha\left(\delta_{\mathrm{H}} 1.73\right)$ and from $\mathrm{H}-17$ to $\mathrm{H}-19$ and $\mathrm{H}-16-\mathrm{Me}$ suggested that $16-\mathrm{Me}$ and $\mathrm{H}-19$ were cofacial and $\alpha$-oriented. Correlations between $\mathrm{H}-16$ and $\mathrm{H}-18-\mathrm{Me}$ and large coupling constants $(J=14.2 \mathrm{~Hz})$ confirmed the double bonds $(\Delta 13$ and $\Delta 17)$ to be E-geometry, and the relative configuration of 1 was identical to that of reported chaetoglobosin B. Therefore, the structure of compound $\mathbf{1}$ was unambiguously assigned by a detailed analysis of the 1D and 2D NMR spectra (Figure 2; Supplementary Figures 1-6). 

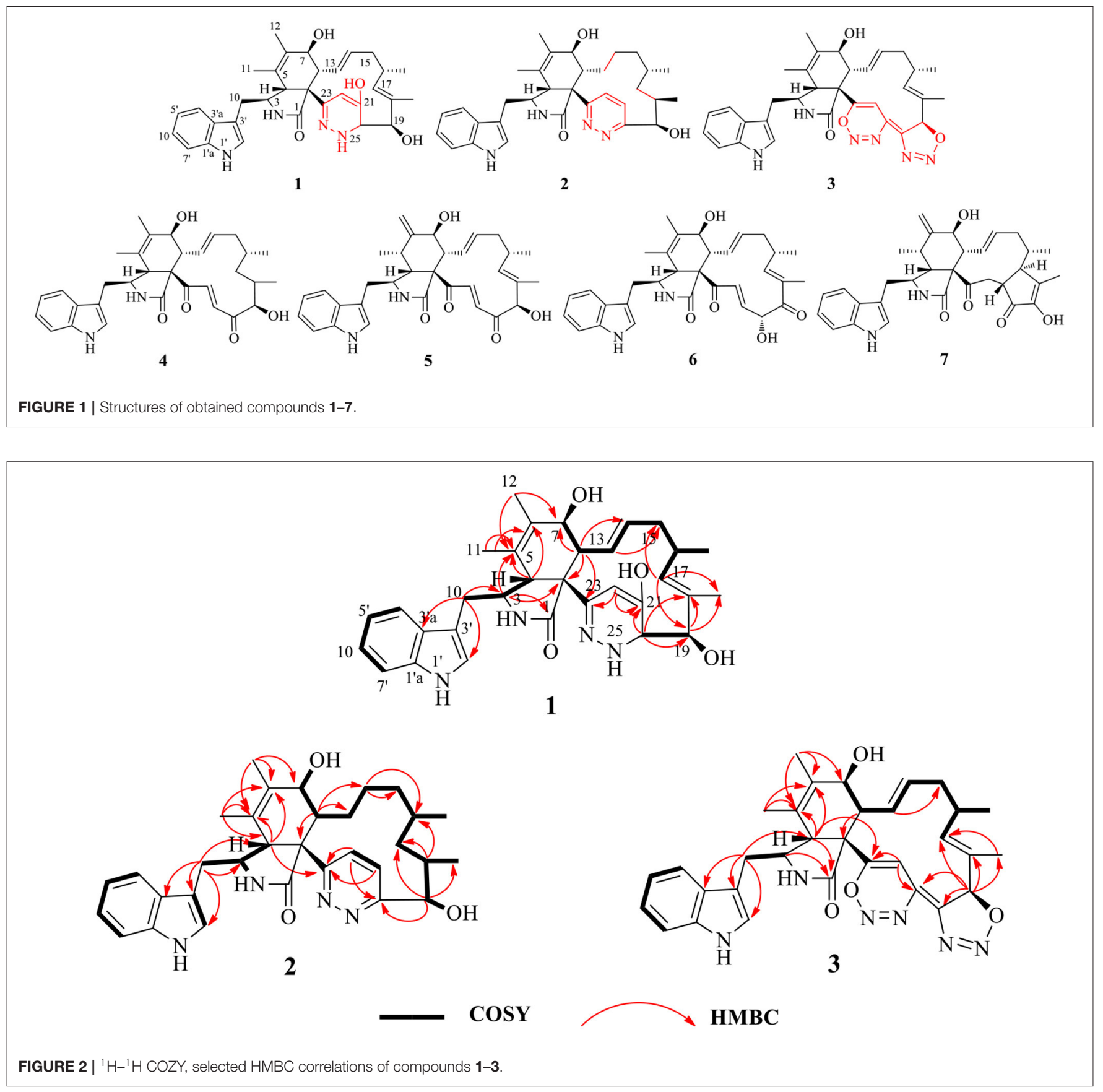

Chaetoglobosin $\mathrm{B}_{2}$ (2) is a white amorphous powder with the molecular formula $\mathrm{C}_{32} \mathrm{H}_{40} \mathrm{~N}_{4} \mathrm{O}_{3}$ (15 unsaturations) as deduced from an ion at $m / z 529.3184[\mathrm{M}+\mathrm{H}]^{+}$in the HR-ESI-MS (Supplementary Figure 17). The comparison of the ${ }^{1} \mathrm{H}$ and ${ }^{13} \mathrm{C}$ NMR data (Tables 1, 2) between 1 and $\mathbf{2}$ showed that both possess a similar chaetogobosin skeleton, with the difference as follows: the four olefinic carbons at C-13 (129.9), C-14 (135.1), C-17 (137.8), and C-18 (133.5) in 1 were replaced by alkyl carbons (C-13, 25.2; C-14, 27.7; C-1730.2; C-18, 34.4) and one amino carbon (73.0, C-20) instead of by an imine carbon (165.5, C-20); the hydroxy group at C-21 disappeared, supported by the proton and carbon resonances at $\delta_{\mathrm{H}} 7.76(\mathrm{br} \mathrm{d}, 8.7, \mathrm{H}-$ 22) and C-21 (125.1) in 2. Furthermore, the observed ${ }^{1} \mathrm{H}^{-1} \mathrm{H}$ COSY correlation (Figure 2; Supplementary Figure 13) of $\mathrm{H}$ $8 / \mathrm{H}_{2}-13 / \mathrm{H}_{2}-14 / \mathrm{H}_{2}-15 / \mathrm{H}-16 / \mathrm{H}_{2}-17 / \mathrm{H}-18 / \mathrm{H}-19$ as well as HMBC correlations (Figure 2; Supplementary Figure 15) from $\mathrm{H}-19$ to C-17, C-18-Me, and C-20, from $\mathrm{H}-21$ to C-22 and C-23, from $\mathrm{H}-22$ to $\mathrm{C}-20$ and $\mathrm{C}-21$, and from $\mathrm{H}-4$ to $\mathrm{C}-23$ confirmed the above deduction. The configuration of 2 at $\mathrm{H}-3, \mathrm{H}-4, \mathrm{H}-$ 7, H-8, and H-16 was defined to be identical to $\mathbf{1}$ and known chaetoglobosin B based on the comparison of the NMR data. The $Z$-geometry of the $\Delta_{21}$-double bond was deduced by the 


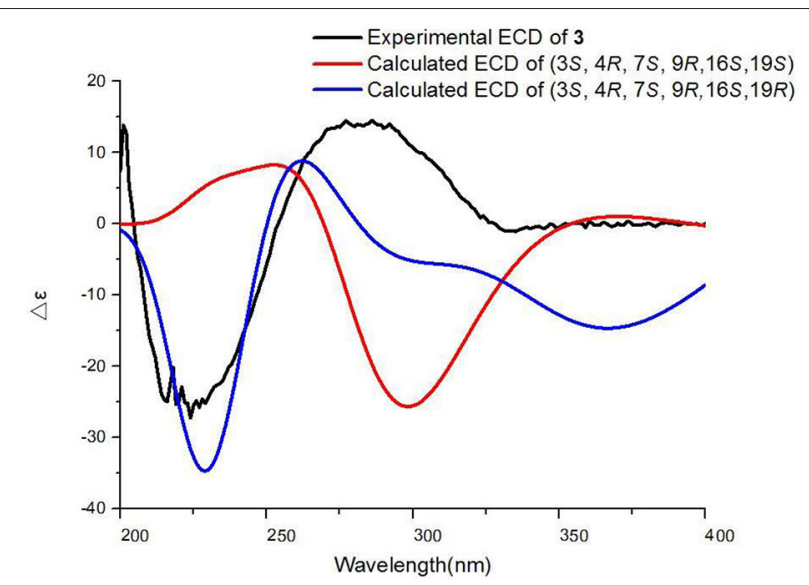

FIGURE 3 | Experimental and calculated ECD spectra of compound $\mathbf{3}$

coupling constant $(J=8.7)$ between $\mathrm{H}-21$ and $\mathrm{H}-22$, and the NOESY correlations (Supplementary Figure 16) of H-16/Me-18 suggested $\mathrm{H}-18$ should be $\beta$-oriented. Therefore, considering the molecular formula and NMR data of 2 , a pyridazine ring fused into the chaetogobosin scaffold formed the structure of 2 .

Chaetoglobosin $\mathrm{B}_{3}$ (3) was obtained as a white amorphous powder. Its molecular formula was assigned as $\mathrm{C}_{32} \mathrm{H}_{34} \mathrm{~N}_{6} \mathrm{O}_{4}$ (19 unsaturations) by HR-ESI-MS (Supplementary Figure 26), which showed a protonated molecule peak at $\mathrm{m} / z 567.2738$ $[\mathrm{M}+\mathrm{H}]^{+}$. The ${ }^{1} \mathrm{H}$ and ${ }^{13} \mathrm{C}$ NMR data (Tables 1, 2; Supplementary Figures 20, 21) suggested compounds 3 and 1 possessed the same core structure except that the heterocyclic incorporated to the 13-membered macrocyclic ring moiety. Comparing the molecular formula of $\mathbf{3}$ and $\mathbf{1}$ suggested the presence of two more nitrogen atoms and four less hydrogen atoms, indicating that two heterocyclic moieties with nitrogen atoms possibly incorporated into chaetoglobosins core structure. However, on the basis of NMR data (Tables 1, 2; Supplementary Figures 20-25) and molecular formula, there may be four possible structures (Supplementary Figure 37) of compound 3. Considering chemical synthesis, the structure of $3 \mathbf{a}$ accords with the reaction production of chaetoglobosin $\mathrm{B}$ and hydrazine monohydrate. To further verify the accurate configuration of C-19 of 3, the ECD experiments and ECD simulation (Figure 3) were both performed. The results corroborated that the configuration of C-19 was established as $19 R$. Thus, compound 3 was named chaetoglobosin $B_{3}$ as shown in Figure 1.

The known cytochalasan alkaloid, chaetoglobosin B (4), chaetoglobosin D (5), chaetoglobosin E (6), and cytoglobosin A (7) were identified by comparing their $1 \mathrm{D}$ NMR and ESIMS data with those in the scientific literature. To make sure that $\mathbf{3}$ is not a scalemic or racemic mixture, an HPLC analysis was carried out on a Agilent 1200 (Agilent Technologies, USA) system with a chiral column Daicel Chiralcel OD-H column (Supplementary Figure 38). The result indicated that 3 is a monomeric compound.

\section{The Plausible Synthesis Pathway}

The putative synthesis pathway for compounds 1-3 was proposed starting from chaetoglobosin B through hydrazinolysis reaction. The precursor chaetoglobosin B underwent an intermolecular nuclephilic addition-elimination reaction with hydrazine, catalyzed by hexahydropyridine to give the intermediates $\mathrm{i}$, followed by [1, 4] addition, ring opening, isomerization, and $[1,5]$ proton transfer reactions led to the formation of $\mathbf{1}$ (Scheme 1A). 2 was formed by an elimination and hydrogenation reduction of intermediates i (Scheme 1A). 3 was an unexpected production of cytochalasan and hydrazine monohydrate. There was little literature on the formation of 3 and its analogs. Herein, we surmised that $\mathbf{3}$ may be not directly produced by cytochalasan and hydrazine monohydrate. Therefore, we propound that $\mathbf{3}$ may be formed by cycloaddition of cytochalasan and the oxidation of hydrazine monohydrate. The plausible pathway of $\mathbf{3}$ is proposed as shown in Scheme 1B.

\section{Biological Activity}

Compounds 1-7 were evaluated for their inhibitory effects toward human non-small-cell lung carcinoma (A549, HCC827), human colon cancer (SW620), and human breast cancer (MDAMB-231) cell lines. As shown in Table 3, compounds 1 and 7 exhibited selected antiproliferative activity on non-smallcell lung carcinoma A549 and human colon cancer SW620 cells, respectively. Compound $\mathbf{4}$ showed selected antiproliferative activity on three cancer cell lines, HCC827, SW620, and MDAMB-231with $\mathrm{IC}_{50}$ values of $11.6,8.8$, and $11.4 \mu \mathrm{M}$, respectively. Compound 5 displayed moderate antiproliferative activity on four cancer cell lines with the $\mathrm{IC}_{50}$ values ranging from 6.9 to $10.6 \mu \mathrm{M}$. It is noteworthy that compound 6 possessed potent activity ( $\mathrm{IC}_{50}$ values ranging from 1.7 to $9.9 \mu \mathrm{M}$ ), which were all stronger than the positive control cisplatin. In addition, compound $\mathbf{6}$ showed a more significant inhibitory effect on two drug-resistant HCC827 cells (Gefitinib-resistant, Osimertinibresistant) with $\mathrm{IC}_{50}$ values of 5.1 and $2.8 \mu \mathrm{M}$, respectively. However, compounds $\mathbf{2}-\mathbf{3}$ showed no obvious inhibitory effect $\left(\mathrm{IC}_{50}>20 \mu \mathrm{M}\right)$. According to the result of the cytotoxicity assay (Tables 3, 4), it is worth noting that the heterocyclic ring fused into the macrocyclic of compounds 1-3 may be reduced the activity by blocking the interaction with its site of action.

\section{CONCLUSION}

As a fungus, the Chaetomium genus contains more than 100 species and plenty of structural novel metabolites (including cytochalasans) with a wide range of biological activities represented from the species ( $\mathrm{Li}$ et al., 2018). To broaden the chemical diversity of cytochalasans with interesting activity, three novel cytochalasan derivatives, termed chaetoglobosins $\mathrm{B}_{1}-\mathrm{B}_{3}(\mathbf{1}-\mathbf{3})$ were isolated from the chemical modification of an extract of C. madrasense 375, and four known metabolite chaetoglobosins (4-7) were also identified. Compounds 13 represented the first examples of hydrazine-containing heterocycle fused into the macrocyclic of cytochalasans. The structures of 1-3 were elucidated by means of spectroscopic data, quantum-chemical ECD simulation. In the antiproliferative 


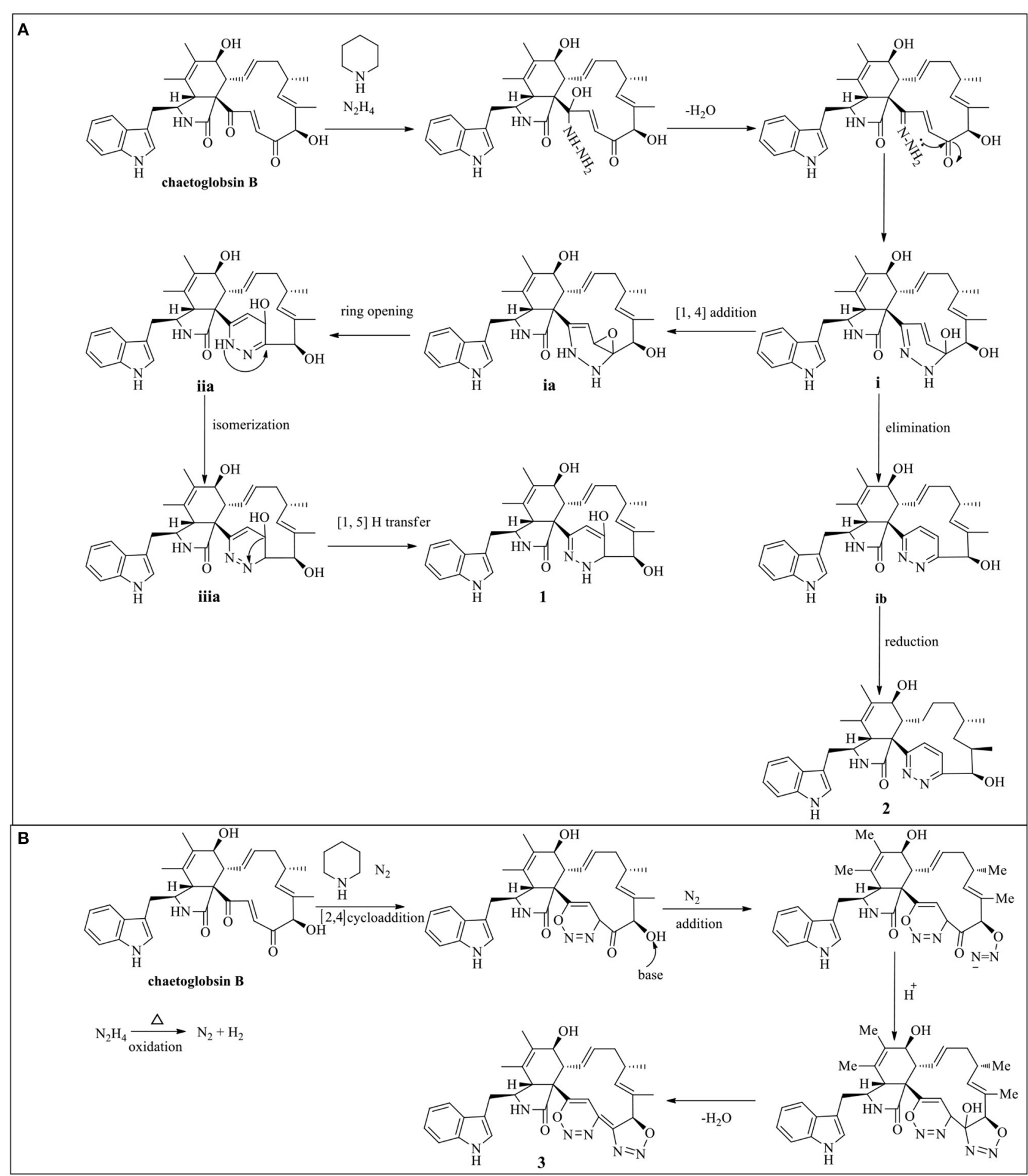

SCHEME 1 | Plausible synthesis pathway of 1-2 (A) and $\mathbf{3}$ (B).

assay, compound 6 displayed potent inhibition activity against four human cancer cell lines (A549, SW620, MDA-MB-231, and HCC827), as well as two drug-resistant (gefitinib, osimertinib) HCC827cell lines; it is the first time to evaluate the drug-resistant activity of cytochalasans. However, the inhibition activity of new compounds 1-3 on three cancer cell lines (SW620, MDA-MB231, and HCC827) was weaker than unreacted chaetoglobosin B (4). Only compound 1 exhibited selected antiproliferative 
TABLE 3 | Cytotoxicity of compounds 1-7 ( $\left.\mathrm{IC}_{50} \mu \mathrm{M}\right)$.

\begin{tabular}{lcccc}
\hline Compounds & A549 & HCC827 & SW620 & MDA-MB-231 \\
\hline 1 & 11.0 & $>20$ & $>20$ & $>20$ \\
2 & $>20$ & $>20$ & $>20$ & $>20$ \\
3 & $>20$ & $>20$ & $>20$ & $>20$ \\
4 & $>20$ & 11.6 & 8.7 & 11.4 \\
5 & 6.9 & 6.9 & 7.7 & 10.6 \\
6 & 2.0 & 1.7 & 2.9 & 9.9 \\
7 & $>20$ & $>20$ & 13.9 & $>20$ \\
cis-platin $^{\mathrm{a}}$ & 6.4 & 4.5 & 4.2 & 47.7 \\
\hline
\end{tabular}

${ }^{a}$ Used as a positive control.

TABLE 4 | Cytotoxicity of compound 6 against two drug-resistant HCC827 cells (Gefitinib-resistant, Osimertinib-resistant) $\left(\mathrm{IC}_{50} \mu \mathrm{M}\right)$.

\begin{tabular}{lcc}
\hline Compounds & $\begin{array}{c}\text { HCC827 (Gefitinib-resistant } \\
\text { strain) }\end{array}$ & $\begin{array}{c}\text { HCC827 } \\
\text { (Osimertinib-resistant } \\
\text { strain) }\end{array}$ \\
\hline 6 & 5.1 & 2.8 \\
Gefitiniba & 65.1 & $-^{\mathrm{b}}$ \\
Osimertinib & $-\mathrm{b}$ & 11.9 \\
\hline
\end{tabular}

a Used as positive controls. ${ }^{b}$ Not tested.

activity on non-small-cell lung carcinoma A549 cells. The results indicated the active sites of 1-3 maybe at C-19-C-23 which were blocked by hydrazine-containing heterocycle. Thus, chemical modification of extract of C. madrasense 375 works not only by considering the modification of the active group but also increasing the site of action in future research. This study provides useful insights that natural products could be an

\section{REFERENCES}

Bradshaw, J., Butina, D., Dunn, A. J., Green, R. H., Hajek, M., Jones, M. M., et al. (2001). A rapid and facile method for the dereplication of purified natural products. J. Nat. Prod. 64, 1541-1544. doi: 10.1021/np010284g

Chen, J. H., Wang, W. F., Wang, H. Y., Liu, X., and Guo, X. (2014). Combination treatment of ligustrazine piperazine derivate DLJ14 and adriamycin inhibits progression of resistant breast cancer through inhibition of the EGFR/PI3K/Akt survival pathway and induction of apoptosis. Drug. Discov. Ther. 8, 33-41. doi: 10.5582/ddt.8.33

Chen, L., Qin, J. C., Zhang, Y. G., and Ding, G. (2020). Diagnostically analyzing ${ }^{1} \mathrm{H}$ NMR spectra of sub-types in chaetoglobosins for dereplication. RSC. Adv. 10, 1946-1955. doi: 10.1039/C9RA10434H

Cui, C. M., Li, X. M., Li, C. S., Proksch, P., and Wang, B. G. (2010). Cytoglobosins A-G, cytochalasans from a marine-derived endophytic fungus, Chatomium globosun QEN-14. J. Nat. Prod. 73, 729-733. doi: 10.1021/np900569t

Feher, M., and Schmidt, J. M. (2003). Property distributions: differences between drugs, natural products, and molecules from combinatorial chemistry. J. Chem. Inf. Comp. Sci. 34, 218-227. doi: 10.1021/ci0200467

Gao, W., He, Y., Li, F., Chai, C., Zhang, J., and Guo, J. (2019). Antibacterial activity against drug-resistant microbial pathogens of cytochalasan alkaloids from the arthropod-associated fungus Chaetomium globosum TW1-1. Bioorg. Chem. 83, 98-104. doi: 10.1016/j.bioorg.2018.10.020 alternative source to generate biological molecules with a novel structure for drug screening through chemical diversification.

\section{DATA AVAILABILITY STATEMENT}

The datasets presented in this study can be found in online repositories. The names of the repository/repositories and accession number(s) can be found in the article/Supplementary Material.

\section{AUTHOR CONTRIBUTIONS}

QG and LC conceived ideas, designed experiments, and wrote the original draft. QG, ZY, and JZ performed the experiments. JC contributed to cytotoxicity testing. YR and BY contributed to the chemical diversification and plausible synthesis pathway. WY, GD, and WZ analyzed the data and critically reviewed the manuscript. XW and GD provided the fungal material. All authors listed have approved the work for publication.

\section{FUNDING}

This work was supported by the Key Scientific Research Projects of Colleges and Universities in Henan Province (20B350004), Tackling-plan Project of Henan Department of Science and Technology (212102310325 and 212102310243), and the special fund project of Zhengzhou basic and applied basic research (ZZSZX202003).

\section{SUPPLEMENTARY MATERIAL}

The Supplementary Material for this article can be found online at: https://www.frontiersin.org/articles/10.3389/fchem. 2021.620589/full\#supplementary-material

Garcia, P., Salazar, M. O., Ramallo, I. A., and Furlan, R. L. E. (2016). A new fluorinated tyrosinase inhibitor from a chemically engineered essential oil. ACS. Comb. Sci. 18, 283-286. doi: 10.1021/acscombsci.6b00004

Guo, Q. F., Yin, Z. H., Zhang, J. J., Kang, W. Y., Wang, X. W., G., et al. (2019). Chaetomadrasins A and B, two new cytotoxic cytochalasans from desert soil-derived fungus Chaetomium madrasense 375. Molecules. 24, 3240. doi: 10.3390/molecules24183240

Kikuchi, H., Sakurai, K., and Oshima, Y. (2014). Development of diversityenhanced extracts of Curcuma zedoaria and their new sesquiterpene-like compounds. Org. Lett. 16, 1916-1919. doi: 10.1021/ol5004324

Li, H., Liao, Z. B., Tang, D., Han, W. B., Zhang, Q., and Gao, J. M. (2018). Polyketides from two Chaetomium species and their biological functions. J. Antibiot. 71, 677-681. doi: 10.1038/s41429-01 8-0047-x

Lopez, S. N., Ramallo, I. A., Sierra, M. G., Zacchino, S. A., and Furlan, R. L. E. (2007). Chemically engineered extracts as an alternative source of bioactive natural product-like compounds. Proc. Natl. Acad. Sci. U.S.A. 104, 441-444. doi: 10.1073/pnas.0608438104

Mendez, L., Salazar, M. O., Ramallo, I. A., and Furlan, R. L. E. (2011). Brominated extracts as source of bioactive compounds. ACS. Com. Sci. 13, 200-204. doi: $10.1021 /$ co $100073 \mathrm{k}$

Newman, D. J., and Cragg, G. M. (2016). Natural products as sources of new drugs from 1981 to 2014. J. Nat. Prod. 79, 629-661. doi: 10.1021/acs.jnatprod.5b01055 
Ramallo, I. A., Sierra, M. G., and Furlan, R. L. E. (2012). Discovery of betaglucosidase inhibitors from a chemically engineered extract prepared through ethanolysis. J. Med. Chem. 8, 112-117. doi: 10.2174/157340612799278559

Salazar, M. O., Micheloni, O., Escalante, A. M., and Furlan, R. L. E. (2011). Discovery of a beta-glucosidase inhibitor from a chemically engineered extract prepared through sulfonylation. Mol. Divers. 15, 713-719. doi: $10.1007 /$ s11030-010-9301-2

Scherlach, K., Boettger, D., Remme, N., and Hertweck, C. (2010). The chemistry and biology of cytochalasans. Nat. Prod. Rep. 27, 869-886. doi: 10.1039/b903913a

Sekita, S., Yoshihira, K., and Natori, S. (1982). Chaetoglobosins, cytotoxic10(indol-3-yl)-[13] cytochalasans from Chaetomium spp. II. Structures of Chaetoglobosins A, B, and D. Chem. Pharm. Bull. 30, 1618-1628. doi: $10.1248 / \mathrm{cpb} .30 .1618$

Sekita, S., Yoshihira, K., and Natori, S. (1983). Chaetoglobosins, cytotoxic10(indol-3-yl)-[13] cytochalasans from Chaetomium spp. IV. Carbon-13 nuclear magnetic resonance spectra and their application to a biosynthetic study. Chem. Pharm. Bull. 31, 490-498. doi: 10.1248/cpb.31.490

Sekita, S., Yoshihira, K., Natori, S., and Kuwano, H. (1976). Structures of chaetoglobosins C, D, E, and F, cytotoxicindol-3-yl-[13] cytochalasans from Chaetomium globosum. Tetrahedron. Lett. 17, 1351-1354. doi: 10.1016/S0040-4039(00)78062-2
Wolfender, J. L., and Queiroz, E. F. (2012). Chemical diversity of natural resources and the bioactivity of their constituents. CHIMIA. 66, 324-329. doi: 10.2533/chimia.20 12.324

Wu, T., Jiang, C., Wang, L., Morris-Natschke, S. L., Miao, H., Gu, L., et al. (2015). 3,5-Diarylpyrazole derivatives obtained by ammonolysis of the total flavonoids from Chrysanthemum indicum extract show potential for the treatment of Alzheimer's disease. J. Nat. Prod. 78, 1593-1599. doi: 10.1021/acs.jnatprod.5 b00156

Conflict of Interest: The authors declare that the research was conducted in the absence of any commercial or financial relationships that could be construed as a potential conflict of interest.

Copyright (c) 2021 Guo, Chen, Ren, Yin, Zhang, Yang, Wang, Yin, Zhang, Ding and Chen. This is an open-access article distributed under the terms of the Creative Commons Attribution License (CC BY). The use, distribution or reproduction in other forums is permitted, provided the original author(s) and the copyright owner(s) are credited and that the original publication in this journal is cited, in accordance with accepted academic practice. No use, distribution or reproduction is permitted which does not comply with these terms. 